The Concentration of Depleted Uranium (DU) and Beryllium (Be) in Soil and Air on Illeginni Island at Kwajalein Atoll after an AHW Flight Test

W. L. Robison, S. C. Yakuma, T. R. Lindman, R.

E. Martinelli, M. W. Tamblin, T. F. Hamilton

November 13, 2012 
This document was prepared as an account of work sponsored by an agency of the United States government. Neither the United States government nor Lawrence Livermore National Security, LLC, nor any of their employees makes any warranty, expressed or implied, or assumes any legal liability or responsibility for the accuracy, completeness, or usefulness of any information, apparatus, product, or process disclosed, or represents that its use would not infringe privately owned rights. Reference herein to any specific commercial product, process, or service by trade name, trademark, manufacturer, or otherwise does not necessarily constitute or imply its endorsement, recommendation, or favoring by the United States government or Lawrence Livermore National Security, LLC. The views and opinions of authors expressed herein do not necessarily state or reflect those of the United States government or Lawrence Livermore National Security, LLC, and shall not be used for advertising or product endorsement purposes.

This work performed under the auspices of the U.S. Department of Energy by Lawrence Livermore National Laboratory under Contract DE-AC52-07NA27344. 


\title{
The Concentration of Depleted Uranium (DU) and Beryllium (Be) in Soil and Air on Illeginni Island at Kwajalein Atoll after an AHW Flight Test.
}

\author{
William L. Robison, Stephen C. Yakuma, Terry R. Lindman, Roger E. Martinelli , \\ Michael W. Tamblin, Steven R. Kehl, Terry F. Hamilton
}

\begin{abstract}
.
An Advanced Hypersonic Weapon (AHW) flight test vehicle impacted on the tarmac surrounding the helipad on Illeginni Island. The exposed soil in the berm created by the impact was analyzed for both $\mathrm{U}$ and $\mathrm{Be}$. The $\mathrm{U}$ concentration in the berm soil is the average concentration for $U$ as observed in the coral soil in the Marshall Islands and other atolls around the world (about $1.9 \mu \mathrm{g} \mathrm{g}^{-1}$ ). The Be concentration in the soil was less than $0.003 \mu \mathrm{g} \mathrm{g}^{-1}$.

The mean concentration of $U$ in 14 samples collected around the tarmac at 1 meter distance from the tarmac is $22 \mu \mathrm{g} \mathrm{g}^{-1}$ that is far below the US EPA guidance for $\mathrm{U}$ in residential soil of $230 \mu \mathrm{g} \mathrm{g}^{-1}$.
\end{abstract}

Similarly, the mean Be concentration in the 14 samples is $2.1 \mu \mathrm{g} \mathrm{g}^{-1}$ that again is far below the USEPA guidance of $160 \mu \mathrm{g} \mathrm{g}^{-1}$ for residential soil.

The concentration of both $U$ and Be in air are many orders of magnitude below the USEPA guidance for the general public.

\section{Introduction.}

On November 11, 2011 a flight test vehicle for the AHW program targeted for Kwajalein Atoll impacted on the tarmac surrounding the helipad (light grey area in Figures 1 and 4. The AHW Hypersonic Glide Body (HGB) contained no DU and very small quantity of a Be alloy. The impact point on Illeginni Island was not in the area where previous flight tests of the Peace Keeper and Minuteman (ICBM) missiles have impacted on the island over many years depositing low concentrations of DU and Be in the soil on the helipad end of Illeginni Island.

During the ICBM missile flight test program a large grid system consisting of many $25 \mathrm{~m}$ by $25 \mathrm{~m}$ squares was established on the contaminated portion of the island in the helipad area (Figure 1). Soil samples were collected on the intersections of the 
rectangles, the midpoints of the sides of the each square, and in the middle of each square. A total of 117 samples were collected and analyzed for $U$ and Be. The results of the analysis of Be and DU in the soil collected from this grid can be found in Reference 1 (Robison et al., 2010) where they are compared with the current USEPA guidance for $U$ and $B e$ in residential soils in the United States. The concentration of Be and DU in air are also summarized in the 2010 report and compared to the latest USEPA guidance for the general public. Some of the 2010 report results will be summarized here as well for the ease of the reader.

After the last ICBM mission the concentration of the DU and Be in the soil were measured over the contaminated "throw-out zone" resulting from the RV impacts on the island. In addition, hi-volume air samplers were run for extended periods of time ( 4 to 6 weeks) downwind of the deposition area after each mission in which a land impact occurred in order to determine the concentration of the DU and Be in air that could potentially be inhaled by persons visiting the island (Robison et al., 2006; Robison et al., 2010).

The USEPA also recommended that the entire contaminated area resulting from the ICBM missile RV impacts on the island should be divided into 0.5 acre parcels and the concentrations of DU and Be should be calculated for each 0.5 acre parcel to compare with the current EPA guidance for residential soils in the United States. The USEPA recommended 3 to 5 samples be collected from each half-acre parcel. We did a much more dense sampling pattern than that as can be seen in Figure 2. The 0.5 acre parcels are color-coded and the results of the DU and Be concentration in the soils of each 0.5 acre parcel are shown in Table 1 and 2 using the same colorcode scheme. The current EPA guidance for both Be and $U$ are listed on the respective figures. The average concentration of DU and Be in the 0.5 acre parcels is far below the EPA guidance for residential soils in the United States.

\section{The AHW impact area and sample collection strategy.}

The AHW vehicle (HGB) impacted on the asphalt tarmac that is about 3 inches deep (the light grey area surrounding the helipad (see Figures 2 and 4). The crater formed as a result of the RV impact produced a circular berm of new soil that has been covered by the tarmac during all the years of the ICBM flight tests and thus represents original coral island soil that is uncontaminated by previous tests. Sixteen total samples were collected from the berm and that includes two duplicate samples of two of the sample sites. The samples were collected at $45^{\circ}, 90^{\circ}, 135^{\circ}$, $180^{\circ}, 225^{\circ}, 270^{\circ}$, and $315^{\circ}$ (Figure 3 ) around the berm.

Fourteen soil samples were also collected at one meter distance from the tarmac around all four sides of the tarmac where DU and Be were deposited during the ICBM flight tests (Figure 4). These samples were collected just to reconfirm previous 
results of Be and $\mathrm{U}$ in the soil because the AHW vehicle impact did not appear to influence this portion of the Island.

The Hi-volume air samplers were positioned downwind from the impact area as shown in Figure 4. The air samplers were run for three weeks and the total volume of air through the filters was about $85,470 \mathrm{~m}^{3}\left(\sim 302,000 \mathrm{ft}^{3}\right)$.

\section{Results}

The resulting concentrations of $\mathrm{U}$ and Be in the air on Illeginni after the AHW impact is shown in Figure 5 as date 2012 on the $\mathrm{X}$ axis. The concentrations of $\mathrm{U}$ and $\mathrm{Be}$ in air are orders of magnitude below the EPA guidance over all the years we made the measurements.

The concentration of the $U$ and Be in the newly exposed soil from the berm caused by the RV impact was $1.9 \mathrm{ug} \mathrm{g}^{-1}$ (Std. Dev. $=0.3$ ) for $\mathrm{U}$ and less than 0.00279 $(\sim<0.003)$ ug g $^{-1}$ for Be. This new value for the Be is much lower than previously reported Be concentrations in coral soil in our other reports. This is the result of increased analytical sensitivity for Be in the ICP mass-spectrometry facility at LLNL. The new value for the Be provides the natural concentration of Be in coral soil and it is very, very low. Thus the Be concentrations in soil previously reported in references 1 and 2 (and repeated here) are definitely a result of the small amounts of Be dispersed upon impact of the ICBM RV's that contained the DU and Be.

The $\mathrm{U}$ concentration of $1.9 \mu \mathrm{g} \mathrm{g}^{-1}$ in the newly exposed berm soil is about the average value for $U$ in coral soils around the world (Robison et al., 2001, 2006, 2010). Mean values for corals around the world range from $1.7 \mu \mathrm{g} \mathrm{g}^{-1}$ to $2.3 \mu \mathrm{g} \mathrm{g}^{-1}$. This is also the range we have found in the Marshall Islands (Robison et al., 2001).

Mean Du concentration for the fourteen soil samples collected in the deposition area of the ICBM tests on all sides of the helipad is $22 \mu \mathrm{g} \mathrm{g}^{-1}$. Thus, the $\mathrm{U}$ concentration around the tarmac is far below the US EPA guidance for residential soils of $230 \mu \mathrm{g} \mathrm{g}^{-1}$.

The Be mean concentration for the fourteen soil samples collected in the deposition area of the ICBM tests on all sides of the helipad is $2.1 \mu \mathrm{g} \mathrm{g}^{-1}$. Thus, the Be concentration around the tarmac is far below the US EPA guidance for residential soils of $160 \mu \mathrm{g} \mathrm{g}^{-1}$.

\section{References:}


1.Robison, W.L., V.E. Noshkin, T.F. Hamilton, C.L. Conrado, K.T. Bogen, (2001), An Assessmentof the Current Day Impact Various Materials Associated with the U. S. Nuclear Test Program in the Marshall Islands. Lawrence Livermore National Laboratory report, UCRL_LR-143980.

2. Robison,W. L., T.F. Hamilton, R.E Martinelli, F.J Gouveia, T.R. Lindman, S. C. Yakuma, (2006), The Concentration and Distribution od Depleted Uranium (DU) and Be in soil and air on Illeginni Island at Kwajalein Atoll. Lawrence Livermore National Laboratory report, Livermore, CA UCRL-TR-222048.

3. Robison, W.L., T.F. Hamilton, R.E Matinelli, F.J. Gouveia, S.R. Kehl, T.R. Lindman, S.C. Yakuma, (2010), Concentration and Distribution of Depleted U (DU) and Beryllium (Be) in soil and air on Illeginni Island at Kwajalein Atoll after the Final Land-Impact Test. Lawrence Livermore National Laboratory report, Livermore, CA LLNL-TR428476.

Figure 1. The location of soil samples collected on Illeginni Island (U, Be concentrations for each site). 


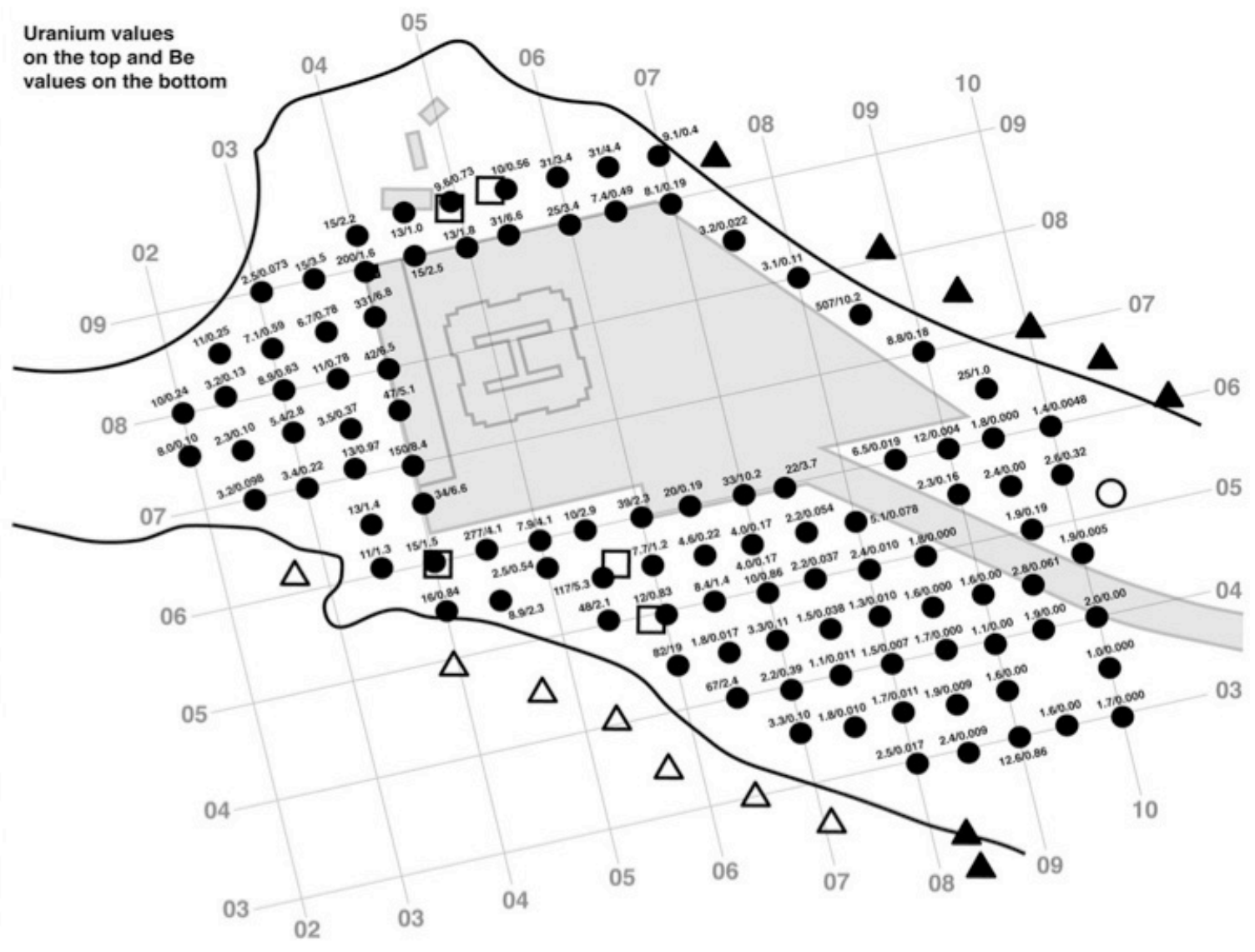

Figure 2. Color-coded 0.5 acre plots sampling sites and data. 


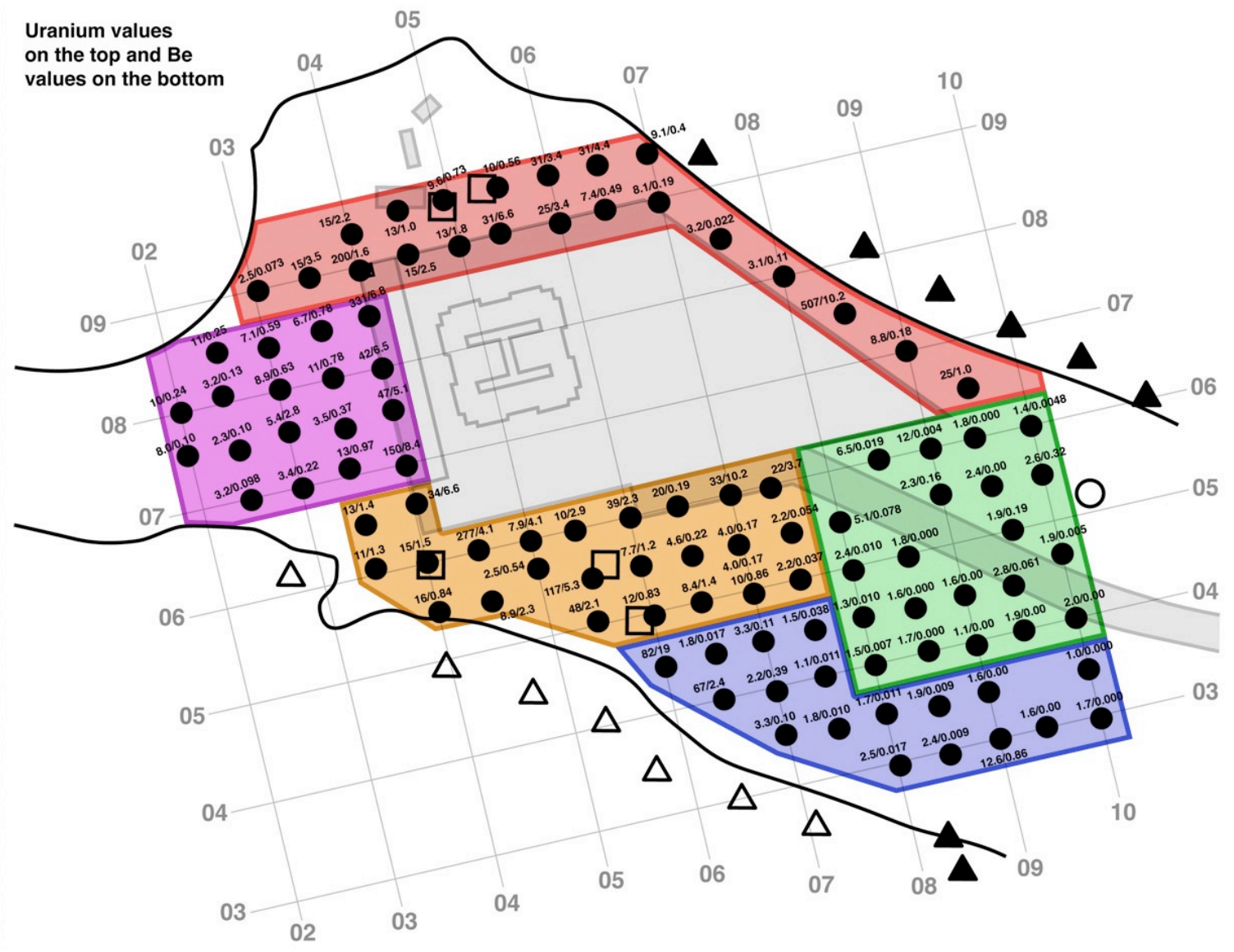

Figure 3. The location of soil samples collected from the berm of the AHW crater. 


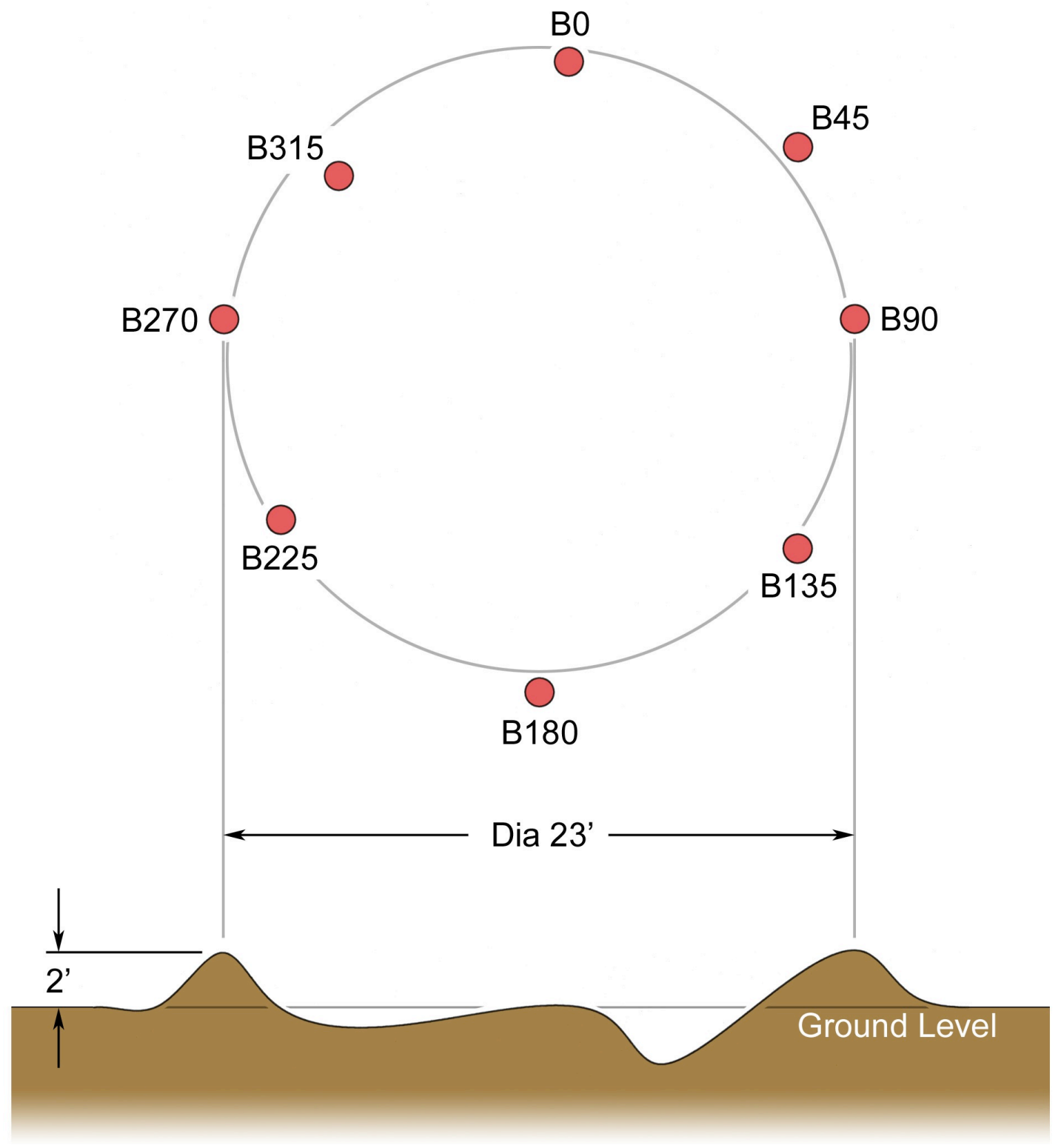

Table 1. The concentration of $U$ in the soil in the five color-coded 0.5 acre parcels and the comparison to current U.S. EPA guidelines. 


\begin{tabular}{|c|c|c|c|c|c|c|c|c|c|}
\hline Coord. & Blue & Coord. & Green & Coord. & Orange & Coord. & purple & Coord. & Red \\
\hline 08,04 & 1.5 & $08.5,06$ & 6.5 & $03.5,06.5$ & $13^{\circ}$ & $02.5,08.5$ & 11 & $04,09.2$ & 15 \\
\hline $08.5,04$ & 1.7 & 09,06 & 12 & $04,06.5$ & 35 & $03,08.5$ & 7.1 & $04.5,09.5$ & 13 \\
\hline 09,04 & 1.1 & $09.5,06$ & 1.8 & $03.5,06$ & 11 & $03.5,08.5$ & 6.7 & $05,09.5$ & 9.5 \\
\hline $09.5,04$ & 1.9 & 10,06 & 1.4 & 04,06 & 15 & $04,08.5$ & 331 & $05.5,09.5$ & 10 \\
\hline 10,04 & 2.0 & $08,05.5$ & 5.1 & $04.5,06$ & 277 & 02,08 & 10 & $06,09.7$ & 31 \\
\hline $08,03.5$ & 1.7 & $09,05.5$ & 2.3 & 05,06 & 7.9 & $02.5,08$ & 3.2 & $06.5,09.5$ & 30 \\
\hline $08.5,03.5$ & 1.9 & $09.5,05.5$ & 2.4 & $05.5,06$ & 10 & 03,08 & 8.9 & $07,09.5$ & 9.1 \\
\hline $09,3.5$ & 1.6 & $10,05.5$ & 2.6 & 06,06 & 39 & $03.5,08$ & 11 & 03,09 & 2.5 \\
\hline $10,3.5$ & 1.0 & 08,05 & 2.4 & $06.5,06$ & 20 & 04,08 & 42 & $03.5,09$ & 15 \\
\hline 08,03 & 2.5 & $08.5,05$ & 1.8 & 07,06 & 33 & $02,07.5$ & 8 & 04,09 & 200 \\
\hline $08.5,03$ & 2.4 & $09.5,05$ & 1.9 & $07.5,06$ & 22 & $02.5,07.5$ & 2.3 & $04.5,09$ & 15 \\
\hline 09,03 & 12.6 & $08,04.5$ & 1.3 & $04,05.5$ & 16 & $03,07.5$ & 5.4 & 05,09 & 13 \\
\hline $09.5,03$ & 1.6 & $08.5,04$ & 1.6 & $04.5,05.5$ & 8.9 & $03.5,07.5$ & 3.5 & $05.5,09$ & 31 \\
\hline 10,03 & 13 & 09,04 & 1.6 & $05,05.7$ & 2.5 & $04,07.5$ & 47 & 06,09 & 25 \\
\hline $06,04.5$ & 82 & $09.5,04.5$ & 2.8 & $05.5,05.5$ & 155 & $02.5,07$ & 3.2 & $06.5,09$ & 7.4 \\
\hline $06.5,04.5$ & 1.8 & $10,04.5$ & 1.9 & $06,05.5$ & 7.7 & 03,07 & 3.4 & 07,09 & 8.1 \\
\hline $07,04.5$ & 3.3 & 08,04 & 1.5 & $06.5,05.5$ & 4.6 & $03.5,07$ & 13 & $07.5,08.5$ & 3.2 \\
\hline $07.5,04.5$ & 1.5 & $08.5,04$ & 1.7 & $07,05.5$ & 4.0 & 04,07 & 150 & 08,08 & 3.1 \\
\hline $08,04.5$ & 1.3 & 09,04 & 1.1 & $07.5,05.5$ & 2.2 & Median & 8.5 & $08.5,07.5$ & 507 \\
\hline $06.5,04$ & 67 & $09.5,04$ & 1.8 & $05.5,05$ & 48 & Mean & 37 & 09,07 & 8.8 \\
\hline 07,04 & 2.2 & 10,04 & 2.0 & 06,05 & 12 & No. & 18 & $09.5,06.5$ & 25 \\
\hline $07.5,04$ & 1.1 & Median & 1.9 & $06.5,05$ & 8.4 & Stdev & 81 & $08.5,06$ & 6.5 \\
\hline 08,04 & 1.5 & Mean & 2.7 & 07,05 & 10 & Stderr & 19 & 09,06 & 1.6 \\
\hline $07,03.5$ & 3.3 & No. & 21 & $07.5,05$ & 2.2 & & & $09.5,06$ & 1.6 \\
\hline $07.5,03.5$ & 1.8 & Stdev & 2.5 & Median & 12 & & & 10,06 & 1.4 \\
\hline $08,03.5$ & 1.7 & Stderr & 0.54 & Mean & 32 & & & $08,05.5$ & 5.1 \\
\hline 08,03 & 2.5 & & & No. & 24 & & & $09,05.5$ & 2.3 \\
\hline Median & 1.8 & & & Stdev & 61 & & & $09.5,05.5$ & 2.4 \\
\hline Mean & 8.0 & & & Stderr & 12 & & & $10,05.5$ & 2.6 \\
\hline No. & 27 & & & & & & & Median & 9.1 \\
\hline Stdev & 19 & & & & & & & Mean & 35 \\
\hline Stderr & 3.8 & & & & & & & $\begin{array}{c}\text { No. } \\
\text { Stdev }\end{array}$ & $\begin{array}{l}29 \\
98\end{array}$ \\
\hline $\begin{array}{l}\text { EPA Dec } \\
\text { Screenin } \\
\mathrm{U}=230\end{array}$ & $\begin{array}{l}\text { mber } \\
\text { Level } \\
\text { ng kg }^{-1}\end{array}$ & 2009 & & & & & & Stderr & 18 \\
\hline
\end{tabular}

Table 2. The concentration of Be in the soil in the five color-coded 0.5 acre parcels and the comparison to current U./S. EPA guidelines. 


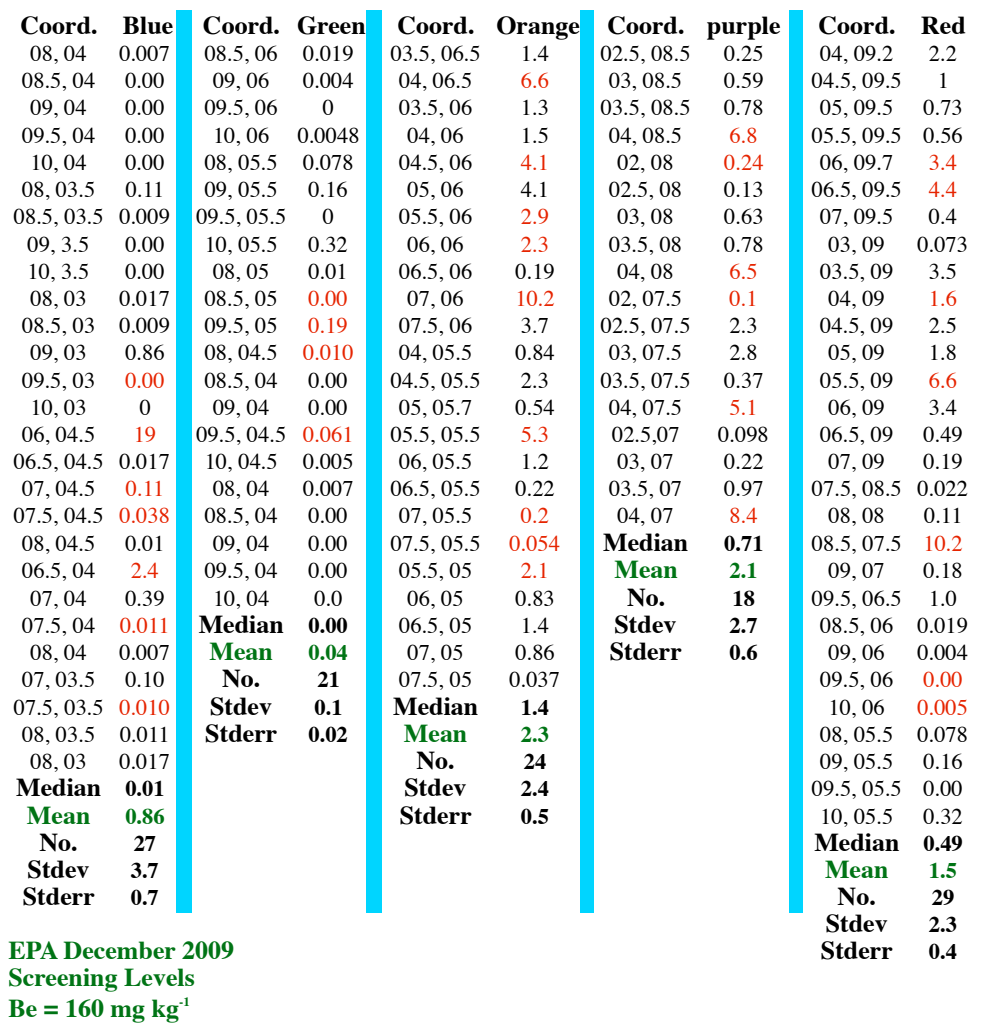


Figure 4. The location of the Hi-volume air samplers after the AHW test and the location of the 14 random sampling sites around the helipad.

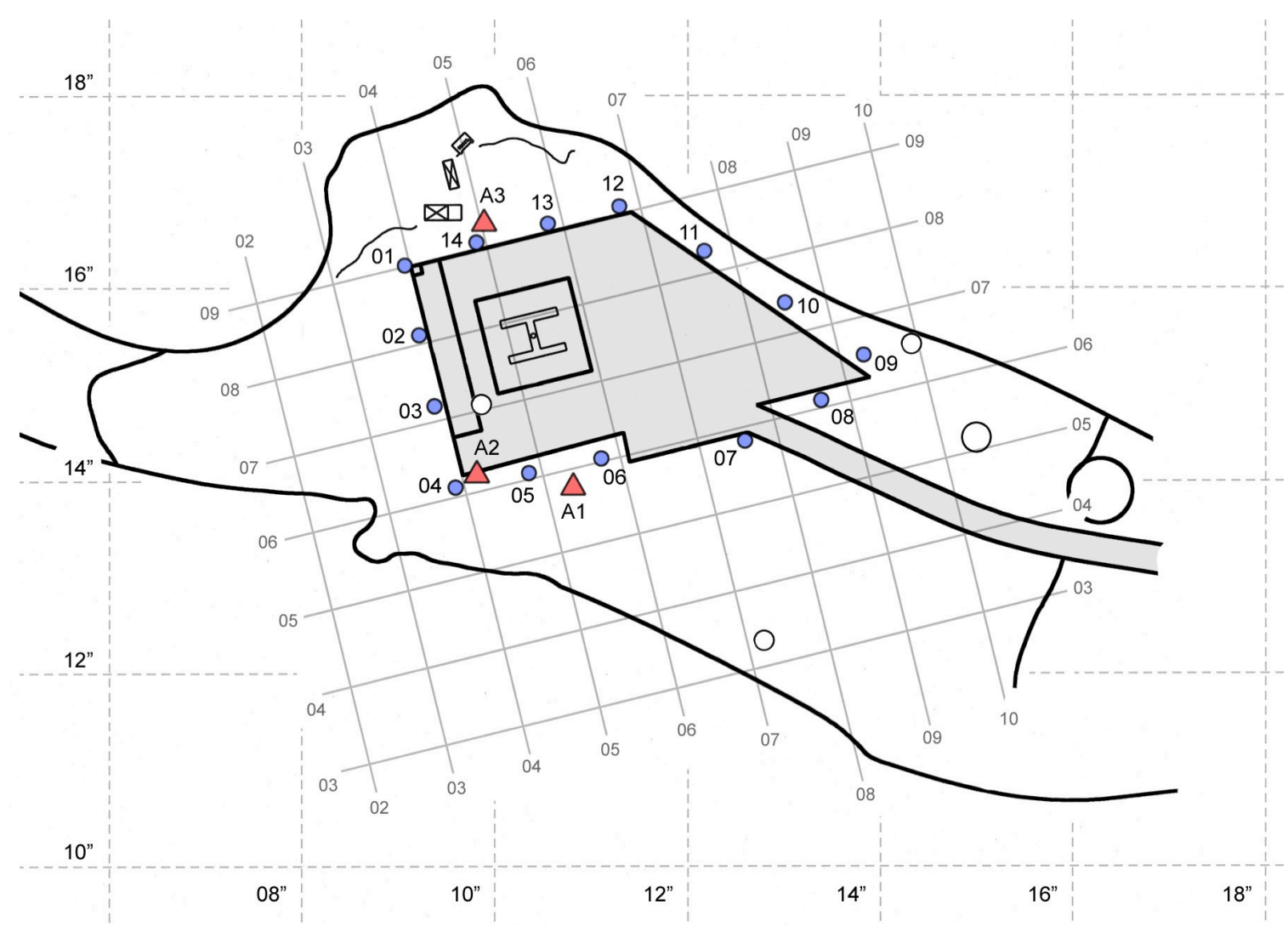

Figure 5. The concentration of the $\mathrm{U}$ and $\mathrm{Be}$ in the air at the Illeginni Island downwind of the U, Be deposition sites in 2012. 


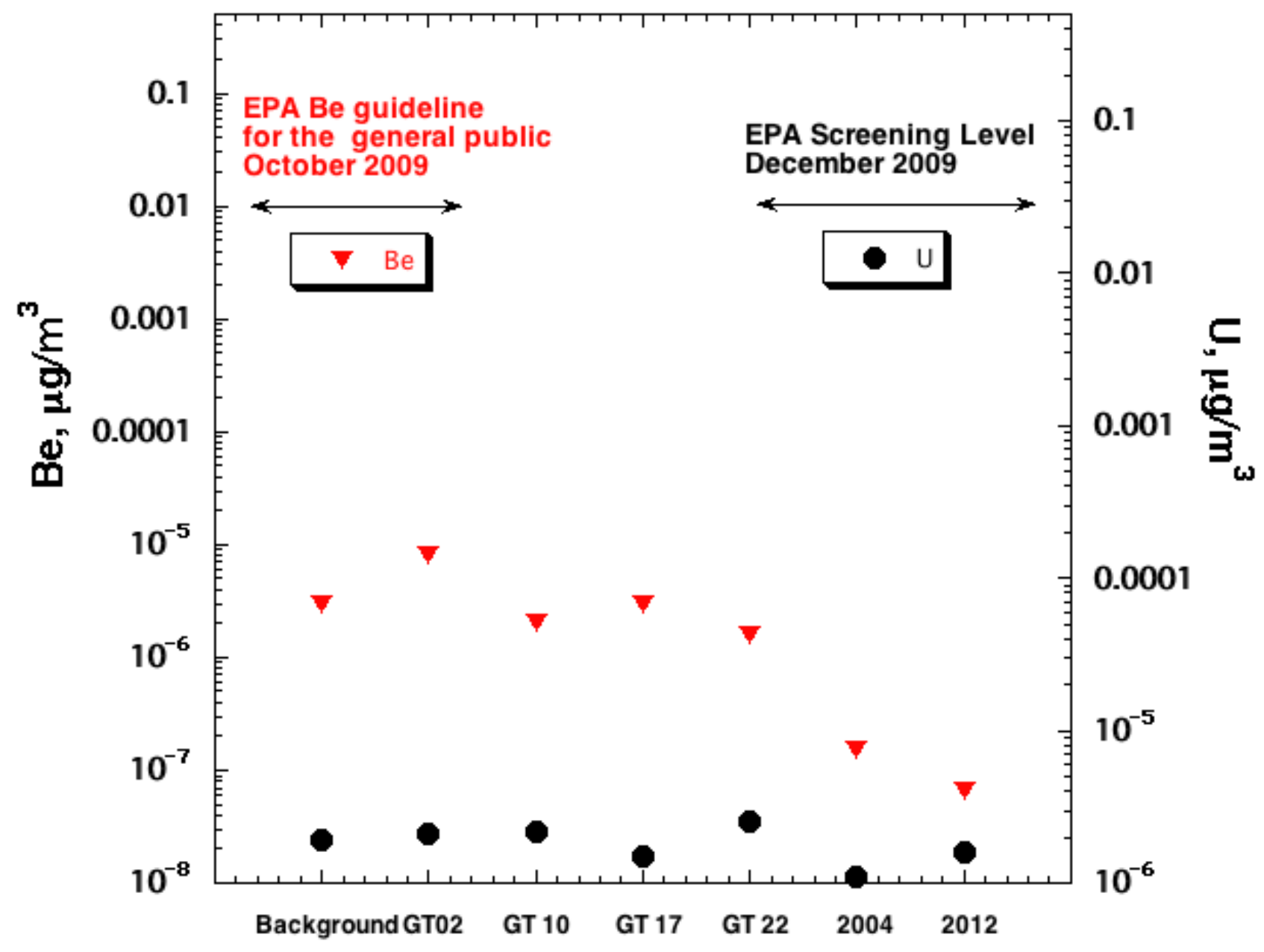

